\title{
Assessing Relative Performance of Econometric Models in Measuring the Impact of Climate Change on Agriculture Using Spatial Autoregression ${ }^{+}$
}

\author{
S. Niggol Seo*
}

\begin{abstract}
Although econometric models have been widely used to measure the impact of climate change on agriculture, there exist differences among the modelers on which specification should be preferred. To help explain the discrepancies, this paper assesses four different econometric models, i.e. OLS, panel, and two spatial models using a South American agricultural household data. The relationship among the econometric specifications is examined in terms of the freedom given to a spatial autoregressive parameter. In spatial models, the spatial parameter is free within the model, but is fixed a priori in the aspatial models. Empirical results show a high correlation of the land values across South America. Spatial models result in somewhat lower climate change impact estimates than those from the aspatial models.
\end{abstract}

Key Words: Climate Change, Agriculture, Land Value, Spatial Dependence, South America JEL Classifications: Q5, Q12, Q15, Q54.

\section{INTRODUCTION}

Econometric models have been widely used to measure the impact of climate change on agriculture in the United States and around the world (Mendelsohn, Nordhaus, and Shaw, 1994, 1996; Kumar and Parikh, 2001; Reinsborough, 2001; Timmins, 2005; Seo, Mendelsohn, and Munasinghe, 2005; Schlenker, Hanemann, and Fisher, 2005; Kurukulasuriya et al., 2006; Deschenes and Greenstone, 2007; Seo and Mendelsohn, 2008a). Using a cross-sectional data, researchers regressed land values or net revenues against climate variables after carefully controlling non-climate factors. Although many cross-sectional studies have been conducted, there still exist substantial discrepancies among the modelers on which specification should be preferred, i.e. whether they should use a weighted OLS (Mendelsohn, Nordhaus, and Shaw, 1994), or a panel model with year and county fixed effects (Deschenes and Greenstone, 2007), or a spatially correlated error model of heating degree days at the county level (Schlenker, Hanemann, and Fisher, 2006). There is a need in the climate research community to assess relative performance of these different econometric models. This task is especially important since previous econometric models resulted in different damage estimates ranging from a slight benefit from climate change (Deschenes and Greenstone, 2007) to a more than 50 percent loss of agricultural income by the mid century (Schlenker, Hanemann, and Fisher, 2006), ${ }^{1}$ which lead to opposing policy recommendations.

\footnotetext{
${ }^{+}$The data used in this study came from a World Bank household survey in South America. I thank the editor and two anonymous reviewers for constructive comments.

* Senior Fellow at the University of Sydney, Address: Faculty of Agriculture, Food and Natural Resources, The University of Sydney, NSW 2006, Australia. Email: niggol.seo@aya.yale.edu.

1 The large loss in U.S. agriculture was attributed by the authors to a proper accounting of irrigation system in the western US States. They limited their analysis to non-irrigated rain-fed farms. Following the authors, this paper will also provide a similar sensitivity analysis focusing on the rain-fed farms.
}

(C) Southern Regional Science Association 2010.

ISSN 1553-0892

SRSA, 1601 University Avenue, PO Box 6025, Morgantown, West Virginia 26506-6025, USA. 
To explain different outcomes among the models, this paper pays particular attention to spatial characteristics of economic data. In contrast to experimental crop models, cross-sectional studies of land values are prone to spatial dependence. That is, land values are determined by their locations (von Thünen, 1826; Hartwick and Olewiler, 1986). For example, two neighboring plots are more likely to have similar values than are two agricultural plots that are further apart. Consequently, econometric models that do not address this spatial nature will result in biased climate parameter estimates because they wrongly assign the difference in land values resulting from spatial dependence to that from climate variation (Anselin, 1988; Dubin, 1988; Benirschka and Binkley, 1994; Olmo, 1995).

With these points in mind, this paper assesses past econometric models in terms of their accounting of spatial dependence in land values. We examine two spatial econometric models, spatial lag and spatial error models, and compare them directly with two aspatial models: OLS and panel models. A systematic comparison is made among the four econometric models on the basis of the freedom given to a spatial autoregressive parameter in each model. Different spatial weight matrices are examined. The four specifications are applied to the agricultural data in South America during the 2003-2004 agricultural seasons. Spatial models are then used to examine whether rain-fed non-irrigated farms are more vulnerable (Schlenker, Hanemann, and Fisher, 2005). The paper also tests whether the damage estimate would depend upon the capacity to adapt (Kelly, Kolstad, and Mitchell, 2005).

\section{A CATEGORY OF ECONOMETRIC MODELS}

The original modelers of the econometric approach applied to a cross-sectional data argued that the method provides an alternative approach to measure the impacts of climate change on agriculture that fully accounts for the possible substitution behaviors of the farmers when climate changes (Mendelsohn, Nordhaus, and Shaw, 1994). This approach has since been applied to the U.S., Brazil, India, Sri Lanka, the United Kingdom, Canada, Africa, and Latin America (Mendelsohn, Nordhaus, and Shaw, 1994, 1996; Kumar and Parikh, 2001; Reinsborough, 2001; Timmins, 2005; Seo, Mendelsohn, and Munasinghe, 2005: Kurukulasuriya et al., 2006; Seo and Mendelsohn, 2008a). Recently, researchers analyzed annual net revenues over multiple years for U.S. agriculture to correct for year-county fixed effects (Deschenes and Greenstone, 2007). Another group of researchers analyzed the sensitivity of the land value in the U.S. to heating degree days while correcting for spatially correlated errors, but the authors relied on the county-level land values (Schlenker, Hanemann, and Fisher, 2006).

All of these models are based on the assumption that each farmer maximizes net revenue subject to the exogenous conditions of his farm. If he chooses optimal outputs $\left(Q^{*}\right)$ and inputs $\left(M^{*}\right)$, then the maximized net revenue will be a function of just the variables that are exogenous to the farmer:

(1) $\pi^{*}=\pi\left(P_{Q}, P_{M}, C, S, W, H\right)$,

where $\mathrm{P}_{\mathrm{Q}}$ and $\mathrm{P}_{\mathrm{M}}$ are output and input prices, $\mathrm{C}$ a set of climate variables, $\mathrm{S}$ a set of soil variables, $\mathrm{W}$ a set of water flow variables, and $\mathrm{H}$ a vector of socio-economic variables. Economists estimated Equation (1) by running a form of OLS regression over a set of independent variables as follows:

(2) $\mathbf{y}=\mathbf{X} \boldsymbol{\beta}+\mathbf{e}$,

(c) Southern Regional Science Association 2010. 
where $\mathbf{y}$ is a vector of land value (or net revenue) per hectare of land, $\mathbf{X}$ a vector of regressors, $\boldsymbol{\beta}$ a vector of parameters, and $\boldsymbol{\varepsilon}=\left(\varepsilon_{1}, \varepsilon_{2}, \ldots, \varepsilon_{n}\right)^{T}$. It is assumed that the error term follows the classical assumption of an independently and identically distributed (iid) normal error distribution.

However, cross-sectionally collected land values are spatially dependent, i.e. land values are determined by its location (von Thünen, 1826; Hartwick and Olewiler, 1986). As the land is further apart from the town center, so does the value of the land decline steadily. An urban land use is no longer profitable at some location beyond which crop land use is more profitable. A land use for crops is no longer profitable at some location beyond which grasslands for livestock are more profitable (See Seo and Mendelsohn [2008b, 2008c] for the discussion of livestock management). And, again, grassland livestock management is no longer profitable at some location beyond which farmers pick fruit and sell timber from the forests.

The spatial dependence of land values can also be thought of as spatially correlated land values. Two neighboring lands are more likely to have similar land values than the two agricultural plots that are farther apart. As the distance from one plot of land to another plot increases, the correlation between the two plots decreases. Farmland values within a village are more similar than they are within a country. Land values within a district are more similar than those within a province.

The existence of spatial dependence can be tested using spatial correlation test statistics. Let's partition a spatial sample of interest, South American farms in this study, into nonoverlapping subsets such that they are exhaustive and exclusive. If land values within each district are assumed to be correlated, then each subset will correspond to each district in the whole sample. Then the spatial lag operator is defined as:

(3) $[W y]_{i}=\sum_{j=1, \ldots, N} w_{i j} \cdot y_{j}$,

where for each row $\mathrm{i}$, the matrix elements $w_{i j}$ are only non-zero for those $j$ in subset $i$ and the $w_{i j}$ equal unity for all $j=1$ to $N$. Consequently, the spatial lag operator is interpreted as a weighted average of the neighboring land values or as a spatial smoother. ${ }^{2}$ The test of spatial auto correlation can be based on the above spatial lag operator. A most cited statistic, Moran's I, is defined as:

(4) $I=\left(N / S_{0}\right)\left(\mathbf{e}^{\prime} \mathbf{W e} / \mathbf{e}^{\prime} \mathbf{e}\right)$,

where $\mathbf{e}$ is a vector of OLS residuals and $S_{0}=\sum_{i} \sum_{j} w_{i j}$. Moran's $I$ is a value that ranges from -1 to 1 and is close to zero when there is little spatial autocorrelation. Another statistic used as often is Geary's $C$, which turns out to be expressed as a function of Moran's I statistic.

The spatial dependence can be modeled explicitly (Anselin, 1988). A simplest form of a spatial model that uses a spatially lagged dependent variable, spatial lag model (SL model), is specified as:

\footnotetext{
${ }^{2}$ We test two different spatial weight matrices in the empirical section.
}

(C) Southern Regional Science Association 2010. 
(5) $\mathbf{y}=\rho \mathbf{W y}+\mathbf{X} \boldsymbol{\beta}+\mathbf{u}$,

where $\rho$ is a spatial autoregressive coefficient and $\mathbf{u}$ is a vector of error terms that are identically and independently normal distributed. The SL model is preferred when authors are concerned about the influence of the spatial dependence on the final outcomes. Note that even though the errors in Equation (5) are independent, land values are correlated, which can be seen by reorganizing the above equation as:

(6) $\mathbf{y}=(\mathbf{I}-\rho \mathbf{W})^{-1} \mathbf{X} \boldsymbol{\beta}+(\mathbf{I}-\rho \mathbf{W})^{-1} \mathbf{u}$.

The SL model is appropriate when researchers want to examine the effects of spatial dependence of farmland values on the estimates of climate change impacts. Another spatial process model, the spatial error (SE) model, is appropriate when researchers are interested in non-spherical error term in which the off-diagonal elements of the covariance matrix express the structure of spatial dependence:

(7) $\boldsymbol{\varepsilon}=\rho \mathbf{W} \boldsymbol{\varepsilon}+\mathbf{u}$,

where all the terms are defined as previously. Using Equations (3) and (7), the SE model is defined as:

(8) $\mathbf{y}=\rho \mathbf{W y}+(\mathbf{I}-\rho \mathbf{W}) \mathbf{X} \boldsymbol{\beta}+\mathbf{u}$.

The parameters in Equations (5) and (8) are estimated by maximum likelihood method or generalized methods of moment. ${ }^{3}$ Past econometric models can be understood as a special case of the SL or SE model by the degree of freedom given to the spatial parameter as follows:

OLS model when $\rho=0$

(9b) Panel model when $\rho=1$

(9c) Spatial model when $\rho$ is not restrained.

First, note that the spatial model should perform best among the three models because the spatial autoregressive parameter $\rho$ is not constrained a priori and determined optimally within the model. Second, the panel model in Equation (9b) is a district (or county in the U.S.) fixed effect model as there is no time component in the data. As the authors correctly stated in the paper, it is difficult to use time series data to measure climate change impacts because there is no variation in the climate year by year as climate is defined as the thirty-year average weather. Land values also cannot be used since there is no variation in the land values year by year (Deschenes and Greenstone, 2007). However, multiple year net revenues (or land values) can be still used to control for the county fixed effects using the SL model in Equation (5). In addition, it is possible to use climate data instead of the year by year weather data using the SL or SE model. Hence, the spatial model is a broader econometric model and should perform best among the econometric models currently used in the literature.

\section{DATA}

The three econometric models in Equations (9a), (9b), and (9c) were applied to South American agriculture data collected throughout the continent during the agricultural seasons

3 This study used maximum likelihood estimation routines outlined by Griffith (1993).

(c) Southern Regional Science Association 2010. 
from 2003 to 2004 (Seo and Mendelsohn, 2008a). As part of a World Bank project, household surveys were conducted from the following seven countries: Argentine, Uruguay, Chile, Brazil, Venezuela, Ecuador, and Colombia. These countries were chosen to cover a broad range of climate zones. Within each country, districts were chosen to represent diverse climate zones within that country. In each country, between 15 and 30 districts were selected and 20 to 30 households were interviewed in each district. Within each county, cluster sampling was done to limit the cost of the survey. The surveys cover agricultural activities during the agricultural period from July 2003 to June 2004.

Temperature data were obtained from the satellites operated by the U.S. Department of Defense, which recorded surface temperature twice daily at the centroids of districts from 1988 to 2004 (Bassist et al., 2001: Mendelsohn et al., 2007). Precipitation data were obtained from the weather station records by the World Meteorological Organization from 1960 to 1990 (WMO, 1989). Seasonal climates are defined by the three-month averages. For example, summer temperature is defined as the average of December, January, and February temperatures in the Southern Hemisphere and winter temperature as the average of June, July, and August temperatures. The seasons in the Northern Hemisphere are defined reversely by switching summer and winter. Soil data were obtained from the Food and Agricultural Organization (FAO) digital soil map of the world CD ROM (FAO, 2001).

\section{EMPIRICAL RESULTS}

The sample is summarized using descriptive statistics of several important variables in Table 1. Temperature is lowest at 9 degrees Celsius in Chile and highest at 20 degrees Celsius in Brazil, Colombia, and Venezuela. Chile is also the driest country with $63 \mathrm{~mm}$ of rainfall per month. Colombia and Venezuela are the wettest places with $132 \mathrm{~mm}$ of rainfall per month. The value of a hectare of land ranges from $\$ 1,000$ to $\$ 2,000 \mathrm{US}^{4}{ }^{4}$ Number of collected surveys varied from fewer than 200 in Ecuador to 700 in Brazil to reflect the size difference of the countries. There was a relatively smaller number of surveys collected from Uruguay and Venezuela, so we added Uruguay to the Argentine sample and Venezuela to the Colombia sample. In both cases, they border each other and have similar geographic and climatic conditions as well as agriculture practices.

TABLE 1: Descriptive Statistics of the Sample

\begin{tabular}{lrrrr}
\hline \hline & $\begin{array}{r}\text { Temperature } \\
\left(\mathrm{C}^{\circ}\right)\end{array}$ & $\begin{array}{r}\text { Precipitation } \\
(\mathrm{mm} / \mathrm{mon})\end{array}$ & $\begin{array}{r}\text { Land value } \\
(\mathrm{USD} / \mathrm{ha})\end{array}$ & $N$ \\
\hline Argentina-Uruguay & 14.81 & 89.22 & 1,418 & 514 \\
Brazil & 20.18 & 118.10 & 2,177 & 694 \\
Chile & 9.34 & 62.57 & 949 & 370 \\
Colombia-Venezuela & 19.45 & 131.58 & 1,959 & 526 \\
Ecuador & 14.25 & 104.14 & 2,198 & 179 \\
\hline \hline
\end{tabular}

\footnotetext{
${ }^{4}$ Land values are directly reported by the farmers with the help from country research teams. The farmland includes both cropland and pasture used for livestock.
}

(C) Southern Regional Science Association 2010. 
As discussed in the theory section, the OLS regression can be seen as a special case of the SL or SE regressions in which the spatial autoregressive coefficient $\rho$ is constrained to zero. We analyze the data using the four econometric specifications: two aspatial regressions and two spatial regressions. Across the four regressions, we keep the same independent variables. ${ }^{5}$

First, we present two aspatial models from Equations (9a) and (9b). A standard OLS regression (Equation (2)) and a panel analysis with county fixed effects are shown in Table 2.6 A most noticeable difference between the two models lies in the significance of the estimated climate parameters. In the OLS, climate parameters are highly significant. But in the panel model, individual climate parameters are mostly not significant. The reason is obvious and was already stated by the researchers that the OLS attributes, wrongly, the difference in land values arising from county fixed effects to that from climate. Once county fixed effects are controlled, climate is less important in the determination of land values across the space (Deschenes and Greenstone, 2007). Soil variables are well identified. Clay soils reduce land values. Flat plains command a higher land value than do steep hills. Soil Phaeozems and Ferralsols increase the value of the land. Other socio-economic variables are also significant. The availability of electricity improves the value of land. Land values are lower in most countries relative to Brazil, which is the omitted category.

From the estimated coefficient itself, it is hard to see what difference it makes to specify the panel model with county fixed effects instead of using a simple OLS model. In Table 3, we calculate the marginal effects of temperature change and rainfall change to compare across the model. A clear difference is that the marginal effects from the panel model are only half of those from the OLS model. Summer and winter temperature effects are reduced by half with the panel model. Winter precipitation effects are also reduced by half. Marginal summer precipitation effects change signs from negative to positive.

To further compare the two aspatial models with two spatial specifications introduced in the theory section, two spatial regression results are shown in Table 4. The Moran's I and Geary's $C$ statistics are shown at the bottom of the spatial regressions to test whether district land values are spatially correlated. The element of the weight matrix $w_{i j}$ is defined to be only non-zero for those $j$ in district $i$ and $\sum_{j=1, \ldots, N} w_{i j}=1$. The Moran's $I$ in Equation (4) tests whether land values in each district are spatially correlated. The Moran's $I$ statistic and Geary's $C$ statistic do not reject the null hypothesis of no spatial correlation. However, the spatial autoregressive parameters in both regressions are very high- 0.85 for both cases.

As in the panel analysis, individual climate parameter estimates are mostly insignificant when spatial dependence is explicitly modeled. In the spatial models, however, most non climate variables have also become insignificant, although the $F$-values are very high for the two regressions.

\footnotetext{
${ }^{5}$ Other control variables such as gender and education of farmers were not significant and were dropped out of the regressions. The distance to the market from each farm was surveyed, but there were too many missing values. Water flow variables were not available.

${ }^{6}$ Following the literature, we used a quadratic functional form of climate variables, summer and winter seasons, and average temperatures and precipitations. The results were robust to the inclusion of temperature and precipitation interaction terms.
} 
TABLE 2: Aspatial Econometric Models of Land Values (USD/ha)

\begin{tabular}{|c|c|c|c|c|}
\hline \multirow[b]{2}{*}{ Variables } & \multicolumn{2}{|c|}{ OLS } & \multicolumn{2}{|c|}{ Panel (country fixed effcts) } \\
\hline & Coefficient & Std. Error & Coefficient & Std. Error \\
\hline Intercept & 4290.00 & 813.38 & -4.40 & 43.75 \\
\hline T sum & 225.60 & 79.50 & -56.24 & 33.56 \\
\hline Tsum sq & -9.45 & 2.34 & 5.77 & 5.81 \\
\hline Twin & 16.30 & 4.79 & -31.23 & 32.13 \\
\hline Twin $s q$ & -0.12 & 0.02 & -3.29 & 4.75 \\
\hline P sum & -98.60 & 58.30 & 7.62 & 5.20 \\
\hline P sum sq & 2.03 & 1.74 & 0.06 & 0.14 \\
\hline$P$ win & -37.10 & 6.26 & -7.74 & 4.83 \\
\hline$P$ Win $s q$ & 0.14 & 0.04 & 0.02 & 0.11 \\
\hline Cambisols & -3.64 & 3.91 & 2.44 & 4.12 \\
\hline Ferrasols & 12.60 & 3.14 & 9.20 & 3.42 \\
\hline Phaeozems & 9.38 & 3.07 & 8.95 & 3.33 \\
\hline Electricity & 504.80 & 136.40 & 149.83 & 125.57 \\
\hline Flat & 407.30 & 103.60 & 143.03 & 119.51 \\
\hline Clay & -338.10 & 133.20 & 43.46 & 142.48 \\
\hline Argentine & -1746.00 & 226.00 & & \\
\hline Chile & -3723.00 & 284.00 & & \\
\hline Colombia & 189.00 & 161.00 & & \\
\hline Ecuador & -1016.00 & 278.00 & & \\
\hline$N$ & 2038.00 & & 2308 & \\
\hline$R^{2}$ & 0.19 & & 0.02 & \\
\hline & 29.06 & & 3.30 & \\
\hline$F$ & $p<0.0001$ & & $p<0.001$ & \\
\hline$\rho$ & & & 1 & \\
\hline
\end{tabular}

(c) Southern Regional Science Association 2010. 
TABLE 3: Marginal Effects and Elasticities on Land Values from the Aspatial Models (USD/ha)

\begin{tabular}{lccrr}
\hline \hline & $\begin{array}{c}\text { Summer } \\
\text { Temperature }\end{array}$ & $\begin{array}{c}\text { Summer } \\
\text { Precipitation }\end{array}$ & $\begin{array}{c}\text { Winter } \\
\text { Temperature }\end{array}$ & $\begin{array}{c}\text { Winter } \\
\text { Precipitation }\end{array}$ \\
\hline & \multicolumn{4}{c}{ OLS } \\
Marginal Effects & -132.11 & -14.50 & -42.23 & -17.51 \\
Elasticities & -1.36 & -1.03 & -0.32 & -0.65 \\
\hline & Panel (county fixed effects) & \\
Marginal Effects & -56.24 & 7.62 & -31.23 & -7.74 \\
Elasticities & -1.04 & -1.55 & -0.14 & -0.44 \\
\hline \hline
\end{tabular}

TABLE 4: Spatial Models of Land Values (USD/ha)

\begin{tabular}{|c|c|c|c|c|}
\hline \multirow[b]{2}{*}{ Variables } & \multicolumn{2}{|c|}{ Spatial Lag } & \multicolumn{2}{|c|}{ Spatial Error } \\
\hline & Coefficient & Std. Error & Coefficient & Std. Error \\
\hline Intercept & 158.8 & 449.2 & 1797.5 & 2802.4 \\
\hline T sum & 68.97 & 49.8 & 451.4 & 281.5 \\
\hline Tsum sq & -2.447 & 1.519 & -14.36 & 8.508 \\
\hline Twin & -0.927 & 1.108 & 7.58 & 16.28 \\
\hline$T$ win $s q$ & 0.001 & 0.003 & -0.062 & 0.071 \\
\hline P sum & 8.61 & 31.7 & -47.14 & 228.6 \\
\hline P sum sq & -0.75 & 0.91 & -1.12 & 6.87 \\
\hline Pwin & -0.507 & 1.13 & -24.79 & 23.74 \\
\hline$P$ Win $s q$ & 0.002 & 0.004 & 0.107 & 0.16 \\
\hline Cambisols & -0.14 & 2.57 & 8.16 & 11.38 \\
\hline Ferrasols & 0.707 & 2.001 & -7.46 & 8.01 \\
\hline Phaeozems & 1.78 & 2.02 & 2.65 & 11.05 \\
\hline Electricity & 68.7 & 88.4 & -18.7 & 111.6 \\
\hline Flat & 53.04 & 66.3 & 273.7 & 357.3 \\
\hline Clay & -40.9 & 86.3 & -483.6 & 396.1 \\
\hline Argentine & -245 & 142 & -1692 & 876 \\
\hline Chile & -526 & 175.8 & -2847 & 1098.5 \\
\hline Colombia & 17.3 & 123 & 578.3 & 775.8 \\
\hline Ecuador & -167.7 & 154 & -1069.4 & 1013 \\
\hline$N$ & 2038 & & 2308 & \\
\hline \multicolumn{5}{|l|}{$R^{2}$} \\
\hline$F$ & 467.7 & $p<0.001$ & $469.23 \mathrm{p}<0.0001$ & $p<0.001$ \\
\hline$\rho$ & 0.84 & & 0.85 & \\
\hline \multicolumn{3}{|c|}{ Spatial Correlation Tests } & $\mathrm{MI}=0.54(p=0.27)$ & $\mathrm{GC}=0.24(p=0.38)$ \\
\hline
\end{tabular}

(C) Southern Regional Science Association 2010. 
TABLE 5: Marginal Effects and Elasticities on Land Values from the Spatial Models (USD/ha)

\begin{tabular}{lcccr}
\hline \hline & \multicolumn{2}{c}{ Summer } & \multicolumn{2}{c}{ Winter } \\
& Temperature & Precipitation & Temperature & Precipitation \\
\hline \multirow{2}{*}{ Marginal Effects } & -23.67 & -0.67 & -12.33 & -0.21 \\
Elasticities & -0.24 & -0.05 & -0.09 & -0.01 \\
& & \multicolumn{2}{c}{ Spatial Lag } \\
Marginal Effects & -12.86 & -1.99 & -11.93 & -1.24 \\
Elasticities & -0.11 & -0.13 & -0.08 & -0.04 \\
& & Spatial Lag with a Provincial Weight Matrix \\
Marginal Effects & -60.41 & -1.48 & -21.76 & -4.98 \\
Elasticities & -0.62 & -0.1 & -0.16 & -0.18 \\
\hline \hline \multicolumn{2}{c}{ Note: Moran’s I for a provincial weights matrix $=0.33, \rho$ for a provincial weights matrix $=0.74}$. &
\end{tabular}

In Table 5, we show the estimated marginal effects and elasticities from the two spatial models. In comparison to the panel model estimates, marginal climate parameter estimates have become even smaller. The marginal temperature elasticities are an order of magnitude smaller than those from the OLS. The precipitation elasticities are also much smaller. Comparing the SE with the SL, marginal effects are even smaller under the SE specification in the case of temperatures, but larger in the case of precipitations. At the bottom panel of the table, we also test whether the above spatial regression results are dependent crucially upon the spatial resolution of the spatial weights matrix. It shows the marginal effects from an alternative spatial weights matrix, which assumes provincial land values, instead of district land values, are correlated. Under this weights matrix, both Moran's $I$ and spatial correlation statistics are smaller than those from the spatial models with the district spatial weight matrix. The marginal temperature effects are twice as large as those of the SL and SE regressions. However, they are twice as small as those of the OLS regression. They are closer to those marginal effects from the panel model with county fixed effects, but marginal winter temperature effect is still much smaller than those of the panel model. Marginal rainfall effects are also smaller than those from the aspatial models.

We ask whether non-irrigated rain-fed farms are more vulnerable to climate change than irrigated farms (Schlenker, Hanemann, and Fisher, 2005). We run a separate regression only on the rain-fed farms using the SL model. We then calculate marginal effects in Table 6. The results reveal that the marginal effects on rain-fed farms are not noticeably different. Except for the winter temperature effects, which are relatively negligible, the estimates are quite close to those of the SL model results from the whole sample. Unlike the results in the U.S., rain-fed farms and irrigated farms in South America are not substantially different in their vulnerabilities to climate change. It is likely that irrigation means much more sophisticated technologies and government interventions in the U.S. than those in the developing countries. Moreover, it is likely that this paper captures irrigation decisions better than the U.S. studies because we rely on individual 
TABLE 6: Sensitivity Analysis from Spatial Models of Land Values (USD/ha)

\begin{tabular}{lcccc}
\hline \hline & \multicolumn{2}{c}{ Summer } & \multicolumn{2}{c}{ Winter } \\
& Temperature & Precipitation & Temperature & Precipitation \\
\hline \multirow{3}{*}{ Marginal Effects } & -24.51 & -2.71 & 3.02 & -3.45 \\
Elasticities & -0.28 & -0.22 & 0.02 & -0.14 \\
& Adaptation Potentials: Limiting to Argentina and Brazil \\
Marginal Effects & -16.79 & -1.01 & -9.79 & -1.36 \\
Elasticities & -0.18 & -0.08 & -0.07 & -0.04 \\
\hline \hline \multicolumn{2}{c}{ Note: $\rho$ for the rain-fed farms $=0.84, \rho$ for the limited sample $=0.88}$.
\end{tabular}

household-level irrigation decisions, whereas previous studies could only discern irrigated and non-irrigated counties.

Another concern frequently raised by researchers is whether farmers will be restrained by their capacities in adapting to climate change in the future (Kelly, Kolstad, and Mitchell, 2005). In our sample, it is likely that the Andean countries have only limited resources to cope with climate change as many of them are small household farms in the high mountains of the Andes (Rosenzweig and Hillel, 1998). To test this hypothesis, we run a separate SL regression by limiting the sample to Argentina and Brazil, excluding the farms in the Andes. Table 6 shows the marginal effects from the two-country regression using the SL model. The results confirm that the two countries are indeed more equipped with the necessary capacity to cope (i.e. marginal effects of summer and winter temperature are smaller than those from the whole sample that includes the Andean countries). However, the difference between the non-Andean sample and the Andean sample does not seem to be very large. The marginal effects from the precipitation variables are not different from those of the whole sample indicating that both the non-Andean and the Andean countries are equally vulnerable to rainfall variations.

\section{CLIMATE SIMULATIONS}

We simulate the impact of climate change assuming several climate scenarios by the middle of this century using both a spatial model and an aspatial model. We utilize the following three Atmospheric Oceanic General Circulation Model (AOGCM) scenarios for 2060 that cover a broad range of climate predictions consistent with recent estimates from the Intergovernmental Panel on Climate Change (IPCC, 2007): the Canadian Climate Center (CCC, Boer, Flato, and Ramsden, 2000); the Center for Climate System Research (CCSR, Emori et al., 1999); and the Parallel Climate Model (PCM, Washington et al., 2000). These scenarios are summarized, by study, for South America in Table 7. The CCC is a hot and dry scenario with a 2.7-degree Celsius increase in temperature and a 10-percent decrease in precipitation. The PCM is a mild and wet scenario with a 1.3-degree Celsius increase in temperature and a 10-percent increase in precipitation. The CCSR predictions fall between the CCC and PCM predictions.

The impact of these climate scenarios on land values is calculated in Table 8 as the difference between the predicted value in 2060 under each climate scenario and the current value using the estimated parameters in Tables 2 and 4. The aspatial model, OLS regression, predicts 
the loss of land values by 20 percent under the CCC scenario, by 25 percent under the CCSR scenario, and by 8 percent by the PCM scenario. The SL model predicts much smaller damage to agriculture. Farmers lose by 6 percent under the CCC, by 4 percent under the CCSR, and by 1 percent under the PCM scenario.

This finding is consistent with a recent study in the U.S. in which authors found that climate change impacts are much muted when county fixed effects are controlled (Deschenes and Greenstone, 2007). However, it is inconsistent with another recent study which found large damage from climate change, more than a 50 percent loss in agricultural income by the middle of the century in U.S. agriculture even with spatial corrections (Schenkler, Hanemann, and Fisher, 2006), but with the county-level aggregate data.

The results imply that the models that do not account for spatial dependence may overstate the damage of climate change on agriculture. To the degree that land values are determined by their spatial locations, spatial specifications should be preferred to aspatial specifications such as the frequently cited county fixed effect model. Spatial effects are more evident in microlevel household data than in county-level aggregate data.

TABLE 7: AOGCM Climate Scenarios for South America

\begin{tabular}{lrr}
\hline & Current & Year 2060 \\
\hline Temperature $\left({ }^{\circ} \mathrm{C}\right)$ & & \\
CCC & 18.1 & $20.8(+2.7)$ \\
CCSR & 18.1 & $20.4(+2.2)$ \\
PCM & 18.1 & $19.5(+1.3)$ \\
Rainfall (mm/month) & & \\
CCC & 119 & $107(-9.5 \%)$ \\
CCSR & 119 & $119(0.0 \%)$ \\
PCM & 119 & $133(+11.9 \%)$ \\
\hline \hline
\end{tabular}

TABLE 8: Land Value Changes by Each Climate Scenario by 2060 (USD/ha)

\begin{tabular}{lcccr}
\hline & \multicolumn{2}{c}{ Aspatial(OLS) } & \multicolumn{2}{c}{ Spatial model (SL) } \\
\cline { 2 - 5 } Scenarios & Change & \% Change & Change & \% Change \\
\hline Baseline & $1,835.22$ & & $1,944.32$ & \\
CCC & $-341.95^{*}$ & -0.19 & $-109.34^{*}$ & -0.06 \\
CCSR & $-450.01^{*}$ & -0.25 & $-87.11^{*}$ & -0.04 \\
PCM & $-144.43^{*}$ & -0.08 & $-21.81^{*}$ & -0.01 \\
\hline \hline Note: * statistically significant with a 5\% level of confidence.
\end{tabular}




\section{CONCLUSIONS}

Although econometric methods have been widely used over the past decades to measure the impact of climate change on agriculture, there is little agreement among the modelers on which specification should be preferred. This paper assesses the four econometric specifications (i.e. OLS, panel, and two spatial models) based on how they treat spatial characteristics of crosssectional data using South American agricultural household data.

This paper emphasizes the need to model spatial dependence explicitly when researchers rely on cross-sectional net revenues or land values. In contrast to the previous studies, this paper analyzes farm-level land value data. The analysis shows that there exists a high spatial correlation of the land values within each district. Accordingly, spatial models result in substantially different impact estimates from those of the aspatial models.

The relationships among the four econometric specifications were examined in terms of the freedom given to the spatial autoregressive parameter. In the spatial models (both the SL and SE models), the spatial parameter is allowed to change freely and is determined in the model. However, in the aspatial models, the parameter is fixed a priori. In the OLS specification, the parameter is fixed to zero. In the panel model, the parameter is fixed to one.

This paper shows that spatial models have more freedom in capturing complex spatial dependence than OLS and county fixed effect models. Empirical analyses indicate that the panel model predicts slightly smaller climate damage to agriculture than the OLS model as was shown in the literature (Deschenes and Greenstone, 2007), but the spatial models predict much smaller climate damage than does the panel model.

The paper also tests whether accounting for irrigation is crucially important (Schenkler, Hanemann, and Fisher, 2005). Unlike the U.S. study, the impact estimates do not differ substantially between irrigated and non-irrigated farms in our study. It is likely because irrigation is more sophisticated and crucial in the west coast U.S. counties than it is in South America. Alternatively, an investigation at the county level may not capture the incentive at the farm level to adopt irrigation or not.

Agricultural experts may be surprised by the results presented in this paper because crops are believed to be highly sensitive to heat and rainfall. This paper, however, does not argue that individual crops are not sensitive to climate. They are indeed highly sensitive (Magrin et al., 2007). What this paper does reveal is that farmers have a large array of crop and livestock varieties to choose from. So if one crop fails under a warmer climate, they are likely to find a better crop or livestock type that can survive under such conditions. Across South America, farmers own a vast variety of assets that have different climate sensitivities such as cereals (wheat, maize, barley, rice, and oats); oil seeds (soybean, peanuts, and sunflower); vegetables/tubercles (potatoes and cassava); a variety of perennial grasses; specialty crops such as cotton, tobacco, tea, coffee, cacao, sugarcane, sugar beets; and tree/shrub crops such as fruits, oil palm, and others. On top of this, farmers own beef cattle across the continent as well as dairy, chickens, pigs, and sheep (Seo and Mendelsohn, 2008a).

On a more cautious note, this paper does not account for the effects of carbon fertilization on agriculture, which is generally believed to be beneficial to crops in the near term (Reilly et al., 1996) but with large uncertainty (Lobell and Field, 2008). Secondly, it also assumes fixed prices, no transition costs, and no technological advance (Cline, 1996: Kelly

(c) Southern Regional Science Association 2010. 
Kolstad, and Mitchell, 2005). However, these factors are likely to remain stable in the near future, not affecting the marginal effect estimates in Tables 3, 5, and 6. Finally, the analysis was not able to control for all the imperfections in the land market. In many parts of Latin America, however, land has been reallocated and land use restricted.

\section{REFERENCES}

Anselin, Luc. (1988) Spatial Econometrics: Methods and Models. Kluwer Academic Publishers: Dordrecht, The Netherlands.

Benirschka, Martin and James K. Binkley. (1994) "Land Price Volatility in a Geographically Dispersed Market,” American Journal of Agricultural Economics, 76, 185-195.

Basist, Alan, Claude Williams Jr., Norman Grody, Thomas F. Ross, Samuel Shen, Alfred T.C. Chang, Ralph Ferraro, and Matthew J. Menne. (2001) "Using the Special Sensor Microwave Imager to Monitor Surface Wetness,” Journal of Hydrometeorology, 2, 297308.

Boer, George, Greg Flato, and D. Ramsden. (2000) "A Transient Climate Change Simulation with Greenhouse Gas and Aerosol Forcing: Projected Climate for the $21^{\text {st }}$ Century," Climate Dynamics, 16, 427-450.

Cline, William. (1996) “The Impact of Global Warming on Agriculture: Comment,” American Economic Review, 86, 1309-1311.

Deschenes, Oliver and Michael Greenstone. (2007) "The Economic Impacts of Climate Change: Evidence from Agricultural Output and Random Fluctuations in Weather," American Economic Review, 97, 354-385.

Dubin Robin. (1988) "Estimation of Regression Coefficients in the Presence of Spatially Autocorrelated Error Terms,” Review of Economic and Statistics, 70, 466-474.

Emori, Seita, Toru Nozawa, Ayako Abe-Ouchi, Atusi Numaguti, and Masahide Kimoto. (1999) "Coupled Ocean-Atmospheric Model Experiments of Future Climate Change with an Explicit Representation of Sulfate Aerosol Scattering,” Journal of Meteorological Society Japan, 77, 1299-1307.

Food and Agriculture Organization (FAO). (2003) The Digital Soil Map of the World (DSMW) CD-ROM. Food and Agriculture Organization: Rome.

http://www.fao.org/nr/land/en/, last accessed in January 2010.

Griffith, Daniel. (1993) Spatial Regression Analysis on the PC: Spatial Statistics Using SAS. Washington, DC: American Association of Geographers.

Hartwick, John and Nancy Olewiler. (1986) The Economics of Natural Resource Use. Harper \& Row: New York.

International Panel on Climate Change (IPCC). (2007) Climate Change 2007: The Physical Science Basis. Summary for Policy Makers, Fourth Assessment Report. World Meteorological Organization: Geneva.

(c) Southern Regional Science Association 2010. 
Kelly, David L., Charles D. Kolstad, and Glenn Mitchell. (2005) “Adjustment Costs from Environmental Change,” Journal of Environmental Economics and Management, 50, 468-495.

Kumar, Kavi and Jyoti Parikh. (2001) “Indian Agriculture and Climate Sensitivity,” Global Environmental Change, 11, 147-154.

Kurukulasuriya, Pradeep, Robert Mendelsohn, Rashid Hassan, James K A Benhin, Temesgen Deressa, Mbaye Diop, Helmy Mohamed Eid, K. Yerfi Fosu, Glwadys Gbetibouo, Suman Jain, Ali Mahamadou, Renneth Mano, Jane Kabubo-Mariara, Samia El-Marsafawy, Ernest Molua, Samiha Ouda, Mathieu Ouedraogo, Isidor Séne, David Maddison, S. Niggol Seo and Ariel Dinar. (2006) "Will African Agriculture Survive Climate Change?,” World Bank Economic Review, 20, 367-388.

Lobell, David and Christopher B. Field, (2008) "Estimation of the Carbon Dioxide (CO2) Fertilization Effect Using Growth Rate Anomalies of CO2 and Crop Yields since 1961,” Global Change Biology, 14, 39-45.

Magrin, Graciela, C. Gay Garcia, D. Cruz Choque, Juan C. Gimenz, Ana R. Moreno, Gustavo J. Nagy, Carlos Nobre and Alicia Villamizar (2007) “Latin America,” In Martin L. Parry, Osfaldo F. Canzianni, Jean .P. Paultikof, Paul J. van der Linden and Clair E. Hanson, eds., Climate Change 2007: Impacts, Adaptation, and Vulnerability. Contribution of Working Group II to the Fourth Assessment Report of the Intergovernmental Panel on Climate Change. Cambridge University Press, Cambridge, UK, pp. 581-615. Available at http://www.ipcc.ch/ipccreports/ar4-wg2.htm in January 2010.

McCarthy, James, Osvaldo F. Canziani, Neil A. Leary, David J. Dokken, and Casey White, eds. (2001) Climate Change 2001: Impacts, Adaptation, and Vulnerability, Intergovernmental Panel on Climate Change Cambridge University Press: Cambridge, UK.

Mendelsohn, Robert, William Nordhaus, and Daigee Shaw. (1994) “The Impact of Global Warming on Agriculture: A Ricardian Analysis,” American Economic Review, 84, 753771.

(1996) “Climate Impacts on Aggregate Farm Values: Accounting for Adaptation,” Agriculture and Forest Meteorology, 80, 55-67.

Mendelsohn, Robert, Pradeep Kurukulasuriya, Alan Basist, Felix Kogan, and Claude Williams. (2007) "Measuring Climate Change Impacts with Satellite versus Weather Station Data," Climatic Change, 81, 71-83.

Nordhaus, William and Joseph Boyer. (2000) Warming the World: Economic Models of Global Warming. MIT Press: Cambridge, MA.

Olmo, Jorge C. (1995) “Spatial Estimation of Housing Prices and Locational Rents,” Urban Studies, 32, 1331-1344.

Reilly, John with many others. (1996) “Agriculture in a Changing Climate: Impacts and Adaptations” in Robert T. Watson, M. Zinyowera, and Richard H. Moss, eds., Climate Change 1995: Impacts, Adaptations, and Mitigation of Climate Change: ScientificTechnical Analyses. Cambridge University Press: Cambridge, U.K., pp. 427-468. 
Reinsborough, Michael J. (2003) “A Ricardian Model of Climate Change in Canada,” Canadian Journal of Economics, 36, 21-40.

Rosenzweig, Cynthia and Daniel Hillel. (1998) Climate Change and the Global Harvest: Potential Impacts of the Greenhouse Effect on Agriculture. Oxford University Press: New York.

Schenkler, Wolfram, Michael Hanemann, and Anthony Fisher. (2005) "Will US Agriculture Really Benefit From Global Warming? Accounting for Irrigation in the Hedonic Approach,” American Economic Review, 95, 395-406.

(2006) "The Impact of Global Warming on US Agriculture: An Econometric Analysis of Optimal Growing Conditions,” Review of Economics and Statistics, 88,113-125.

Seo, S. Niggol and Robert Mendelsohn. (2008a) "A Ricardian Analysis of the Impact of Climate Change on South American Farms,” Chilean Journal of Agricultural Research, 68, 69-79. . (2008b) "Measuring Impacts and Adaptations to Climate Change: A Structural Ricardian Model of African Livestock Management,” Agricultural Economics, 38, 151-165.

. (2008c) “Animal Husbandry in Africa: Climate Change Impacts and Adaptations," African Journal of Agricultural and Resource Economics, 2, 65-82.

Seo, S. Niggol, Robert Mendelsohn, and Mohan Munasinghe. (2005) “Climate Change and Agriculture in Sri Lanka: A Ricardian Valuation,” Environment and Development Economics, 10,581-196.

Timmins, Christopher. (2005) "Endogenous Land Use and the Ricardian Valuation of Climate Change,” Environmental and Resource Economics, 33, 119-142.

von Thünen, Johann H. (1826) The Isolated State. (Translated by Carla M. Wartenberg, Oxford, New York, Pergamon Press [1966]).

Washington, Warren, John Weatherly, Gerald Meehl, Albert Semtner, T. Bettge, A. Craig,W. Strand, J. Arblaster, V. Wayland, R. James, and Y. Zhang. (2003) "Parallel Climate Model (PCM): Control and Transient Scenarios,” Climate Dynamics 16, 755-774.

World Meteorological Organization (WMO). (1989) Calculation of Monthly and Annual 30-year Standard Normals, WCDP-No. 10. WMO-TD/No. 341. World Meteorological Organization: Geneva. 